\title{
Energy metrics for European residential buildings for cities, towns\&suburbs and rural areas - the case of Romania
}

\author{
Vasile Dogaru ${ }^{1, *}$, Ioan Silviu Dobosi ${ }^{2}$ \\ ${ }^{1}$ West University of Timisoara, Nicholas Georgescu-Roegen Interdisciplinary Platform, 300223 Vasile Parvan 4A/704C, Romania \\ ${ }^{2}$ Dosetimpex SRL, General Manager, 300714 Calea Buziasului 11, Timisoara, Romania
}

\begin{abstract}
The report of The International Energy Agency summarizes the energy use for European Union cities in 2006 by 1259 Mtoe (3.46 toe per capita) and predicts an yearly increase by $0.73 \%$ until 2015 and by $0.4 \%$ between $2016-2030$. The projection for the first increase has not been reached for EU residential urban buildings. The world energy use for buildings is about $40 \%$. Some EU countries have no disaggregated data for urban-rural areas, for cities, towns and suburbs and rural areas. We are modeling Romania's residential building energy between 2001-2016 for the three levels mentioned above. In the following period, the rural buildings energy per capita will overcome the urban level of cities, towns and suburbs in Romania, in line with other EU countries. The distinct metrics for employees and pensioners were modeled by policy makers in cities, towns and suburbs and rural areas. The quantity of energy use was also modeled for the three levels. The downwards trend for household energy use in cities as compared to rural areas is identified for the 2001-2016 period for Romania. The EU energy use figures for cities will underline the more efficient allocation of structural funds for the next programming period 2021-2027.
\end{abstract}

\section{Introduction}

The report of The International Energy Agency [1] summarizes the urban energy use in 2006 by 1259 Mtoe (3.46 toe per capita as gross energy consumption) for the European Union (EU-27) and in other two main regions: 1,865 Mtoe for US, 1,424 Mtoe for China and 109 Mtoe for Australasia. The predicted yearly increase for EU-27 is by $0.73 \%$ until 2015 and by $0.4 \%$ between $2016-2030$. According to Eurostat figures, the EU-27 level of energy use for residential buildings for 2006-2015 decreased by $0.11 \%$ every year and $9.3 \%$ per total during this period. The building energy consumption of some EU cities, located in the Western developed countries, was registered in public databases until 2007. To the best of our knowledge, the projection for worldwide urban energy use for these regions has not been revised for the 2015-2030 period.

Quantitative and value (in monetary terms) evaluation are rarely integrated into the urban or rural energy consumption analysis of buildings (3-4 citari din bibliografia selectata, eventual cu TEXT). For some countries, we could discuss overcoming poverty $[2,3]$ in monetary terms, in relation to the spatial distribution of building energy consumption. The setting of maximum amounts of energy consumption for buildings is linked to the macro targeting levels made by the EU and its Member States through public decisions.

The quantity of building energy use in cities, towns and suburbs and rural areas strongly depends on the income spent on goods and services.
To discover the relation between the quantity and quality (income spent) of energy use it is necessary to measure the elasticity for energy use.

The quantity of energy use for European Union residential areas is set through limits on the building surface unit for Romania and other European Union countries after 2020. The target levels for buildings that could be reached in the EU, in the next period could not be correlated with the population's investment capacity from a medium household's budget in order to achieve energy reduction. In US, under similar conditions, some efficiency standards set by law for the energy use of the population have been canceled in court [4].

The assessment of the quantity of energy use by types of human settlements is currently carried out at EU level. The macro valuation of the building energy saving for some EU strategies uses monetary figures and in some cases, it is done by the fuel quantities [5-7]. In the basic studies for these strategies, the data on energy use, both in monetary and quantitative terms for EU urban and rural areas, are missing for the three levels of settlement. The 20-20-20 Strategy uses the total energy monetary figure (consumption expenditure) as the unique figure for the EU target. The new Heating and Cooling Strategy ( $\mathrm{H} \& \mathrm{CS}$ ) has modeled on a more detailed framework for setting the targets for cities, towns and suburbs and rural areas (CT\&SRA) by using the other classification, of metropolitan and nonmetropolitan regions. The assumed overlapping of metrics for metropolitan and non-metropolitan regions over the figures in urban or rural areas is not proven in

Corresponding author: vasile.dogaru@e-uvt.ro 
this case. The IEA figures [1] for EU count the energy quantities for the two levels, for CT\&S and for RA.

Some recent studies are measuring (estimative) the increase of city pollution (by over $70 \%$ ) in the following decades. Generally, the relative (\% in total) level of urban energy consumption is considered to be similar to relative urban pollution. In the $\mathrm{EU}$, for the following decades, the two national trends are expected to reduce the energy consumption of each country (in the EU) and reduce (relatively higher) the related pollution. The relatively linear link, at European or national level, between lowering energy consumption in buildings and reducing $\mathrm{CO} 2$ pollution by 2020 , requires, in the next decades, a new, distinct modeling for urban and rural areas. In order to achieve the two national targets, the national energy process ought to be spatially fragmented for buildings by the type of settlement and the related figures needed to be modeled. Some cities have set another time-neutral spatial CO2 target at local level [8] or even for urban micro-areas [9].

Some databases have partial information for some countries on the three levels of human settlements. The data were collected every 5 years by national institutes and then by Eurostat. In the New Member States (NMC12) the European energy consumption survey is at the beginning. In some countries, the data was collected only on 2 levels, in urban and rural areas. The first study on the energy consumption of buildings in Romania, for urban and rural areas, uses data collected for 2009 [10]. Data for the new intermediary level, towns and suburbs, are influenced by the time axis at European and national level by the population structure. In Romania, this population has had a high fluctuation. This fluctuation was also found in other European countries, such as Greece.

The preparation of the EU 2021-2027 programming period, opened the discussion on the orientation of the priority allocation of structural funds for cities or suburbs to better support the economy of scale. The spatial modeling of energy and pollution in cities and separately in suburbs and towns requires appropriate modeling of data to avoid the concentration effect of energy use and pollution in buildings in order to reduce the negative effects in the coming decades.

The purpose of this article is to spatially model the energy use for buildings in Romania on the three types of human settlements. Quantitative and value metrics provide the basis for the spatial energy policies of buildings in Romania after 2020, given the different trends of energy and related pollution in 2020-2050.

\section{Methods}

The modeling of energy was done for every combination of $\mathrm{HH}$, settlement, for every year (20012016), and for quantity and consumption expenditure on fuel using the framework created by the formula (1), (2) and (3). The explanations are given further.

The calculation of the quality of energy use (income spent) was done by summing up all the consumed products (gas, power, solid fuel, RES, thermal heating) and related services. Previously, these products and services were segmented from over 236 total products and services for HH. Subsequently, all the products for energy use were assigned to energy consumption (CP045 code) according to the COICOP classification.

Household energy for buildings in urban and rural areas was subsequently modeled to shift to three-level classifications by modeling the segmentation of T\&S consumption. The bottom-up modeling was done by identifying the 205 towns and the 201 suburban rural settlements in Romania. Energy consumption for buildings $(\mathrm{HH})$, for $\mathrm{C} \& \mathrm{~T}$ and for the three levels, for the entire population, for employees and pensioners has been temporary and spatially modeled. The total energy use for $T \& S$ was calculated according to the population structure. The number of people per household for T\&S was modeled according to the population of the towns and suburbs and related figures for cities and rural areas.

The resident population as of January 1 for $\mathrm{C} \& \mathrm{~T}$ was extrapolated for 2001-2016 using the 2010 and 2011 data from Eurostat (2019) and National Institute of Statistics of Romania (2019) databases. Energy consumption has been modeled by using the resident population as of 1 January. The total energy use and per $\mathrm{HH}$ have different levels if the metrics are modeled using the stable population. Metrics may also differ if the resident population is used from July 1 . In our research, there is no distinction between the energy consumption of the $\mathrm{HH}$ and the energy consumption of the building.

Energy use in quantities was also modeled for the $\mathrm{C}, \mathrm{T} \& \mathrm{~S}$ and RA levels, for workers, pensioners and the entire population, for each year, from 2001 to 2016 . It was considered a unique structure of fuels used to heat and cool the buildings and the same unit prices of fuels in the three types of settlements. The hypothesis of the unique structure of fuel type was also maintained in the analysis of the three types of households: total population, employees, pensioners.

$E v t($ total $)=\mathrm{SUM}_{\mathrm{i}} \mathrm{SUM}_{\mathrm{j}} \mathrm{SUM}_{\mathrm{k}}\left(f v_{\mathrm{ijk}}\right) * N m * N o H H c_{\mathrm{ij}} *$
$\left.N o H H_{\mathrm{ij}}\right)$

For every combination (96 cases) of $\mathrm{HH}$ and settlement, $i$ si $j$ and for every year 2001-2016

$$
\begin{aligned}
& \left.E v t \mathrm{ij}=\operatorname{SUM}_{\mathrm{k}}\left(f v_{\mathrm{ijk}}\right) * N m * N o H H c_{\mathrm{ij}} * N o H H_{\mathrm{ij}}\right) \\
& e_{\mathrm{vcij}}=\operatorname{SUM}_{\mathrm{i}} \operatorname{SUM}_{\mathrm{j}}\left[F v t \mathrm{ij} /\left(N o H H c_{\mathrm{ij}} * N o H H_{\mathrm{ij}}\right)\right]
\end{aligned}
$$

To calculate the metrics for employees and pensioners, we used population and household weights on the total level.

\section{Calculation and results}

The tables and the figures with the results are as follows. 


\begin{tabular}{|l|l|l|l|}
\hline Index & \multicolumn{1}{|l|}{ T } & E & P \\
\hline I total & 1.13 & 1.01 & 1.18 \\
\hline I C & 0.95 & 0.95 & 0.92 \\
\hline I T\&S & 1.04 & 1.04 & 0.93 \\
\hline I RA & 1.45 & 1.23 & 1.51 \\
\hline I $_{\text {RA/C }}$ & 1.52 & 1.29 & 1.64 \\
\hline
\end{tabular}

Table 1 Energy use (koe) index for HH, Romania, 200116 , total (T), employees (E) and pensioners (P)

\begin{tabular}{|l|r|r|r|r|}
\hline Year & \multicolumn{1}{l|l|}{ T } & \multicolumn{1}{l|}{ C } & \multicolumn{1}{l|}{ T\&S } & \multicolumn{1}{l|}{ RA } \\
\hline 2001 & 165 & 196 & 180 & 128 \\
\hline 2006 & 524 & 586 & 551 & 447 \\
\hline 2011 & 847 & 887 & 864 & 799 \\
\hline 2016 & 1,135 & 1,141 & 1,137 & 1,128 \\
\hline
\end{tabular}

Table 2 Energy consumption for residential buildings, Romania, C, T\&S, RA, total HH, 2001-2016, lei/capita

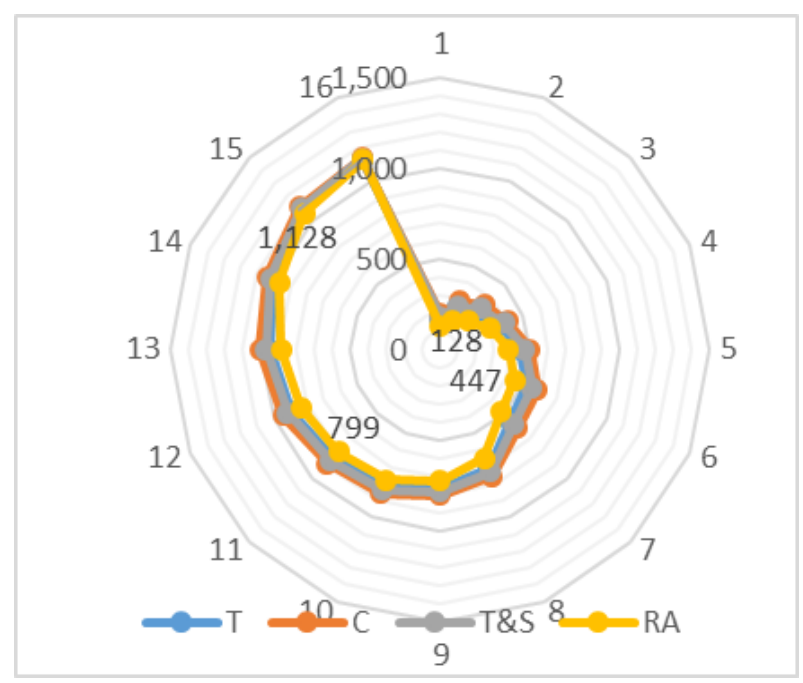

Fig. 1 Helix of energy consumption for residential buildings, Romania, C, T\&S, RA, total HH, 2001, 2006, 2011 and 2016, lei/capita

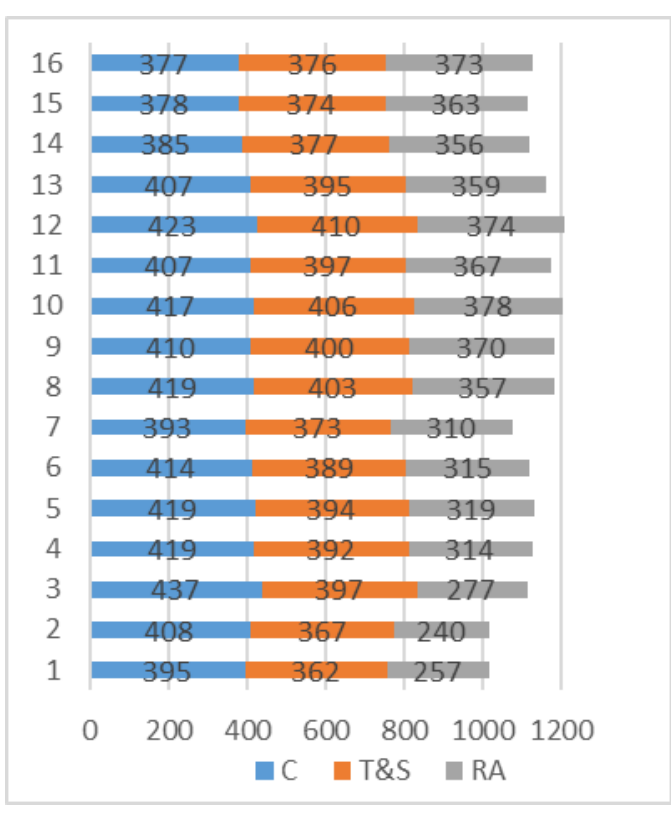

Fig. 2 Energy use for residential buildings, Romania, C, T\&S, RA, total HH, 2001-2016, koe/capita

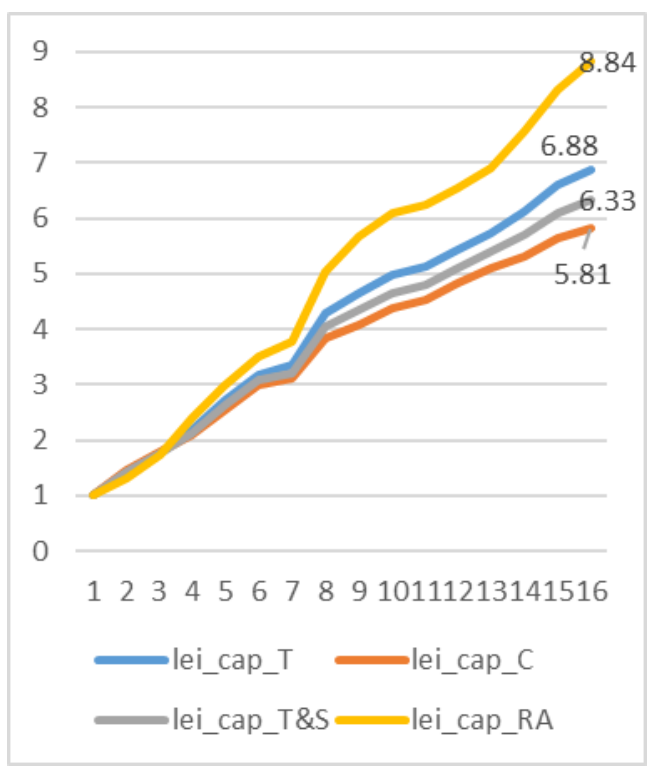

Fig. 3 Energy consumption indexes for residential buildings, Total, C,T\&S, RA, Romania, total HH, lei/capita, 2001-2016, 2001=1 


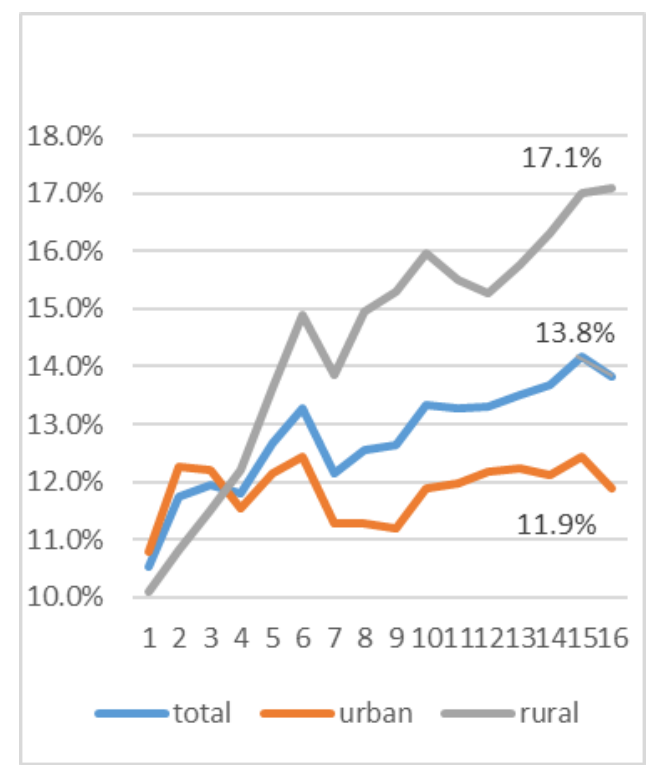

Fig 4 The poverty energy (threshold) for residential buildings, total, urban and rural, Romania, total $\mathrm{HH}, \%$ consumption expenditure, 2001-2016

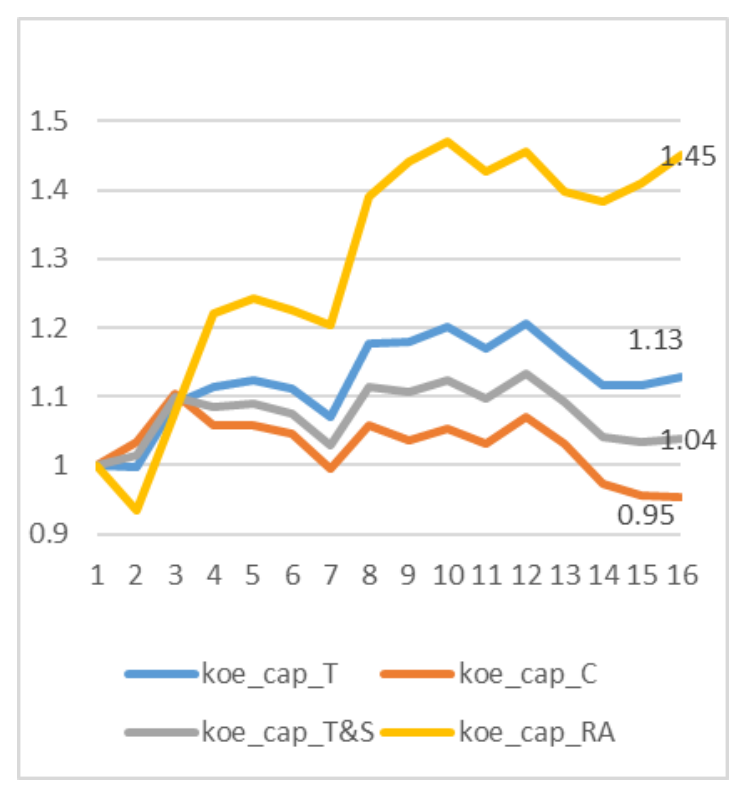

Fig. 5 Energy indexes for residential buildings, $\mathrm{T}$, C,T\&S, RA, Romania, total HH, koe/capita, 2001-2016, $2001=1$

\section{Discussions}

The relatively linear link at European or national level between reducing energy consumption in buildings and reducing $\mathrm{CO} 2$ pollution by 2020 for buildings will be differentiated by the modeling done for the next decades, separated for urban and rural areas. Spatial modeling of energy and indirect (further) of pollution in large cities, and separately in suburbs and towns, can provide decisions to avoid the effect of concentration of energy consumption and pollution in buildings. As a result, negative effects can be mitigated in the coming decades.
For Romania, the energy use figures were modeled for the 2001-2016 period using the quantity and monetary terms of energy use, for the three levels of settlements, avoiding the non-metropolitan and metropolitan region classification. The new metrics for Romania accomplish the classification criteria for overlapped metrics (assigned) on the right spatial process [10].

Romania proposes to achieve the objective established by Directive 31/2010 - intensity of pollution over the next three decades to proportionately reduce energy use. This aims at precisely attenuate the effect of human density and residential buildings.

Spatial computing and the calculation of pollution in large cities and, separatedly, in suburbs and cities requires appropriate data modeling so that the effect of concentrating energy consumption and pollution of buildings does not produce greater negative effects over the coming decades.

The data collected in Romania for 2009 [11] did not serve to fill the Eurostat base for 2010. Data on HH's energy consumption were recalculated (extrapolated) from 2001 onwards for two levels. They allowed data to be completed for 2015 at the value level reported for the EU official databse (Eurostat) in October 2018 for three levels. Data for T\&S energy needs to be carefully considered at European level. The population in suburbs and small towns in Romania had a high fluctuation by the reclassification of rural settlements as suburbs and towns. These data oscillations model different energy consumption times in a household.

The modeled residential population for the 20012016 period was used to further model the total initial consumption figures for each of the three characteristics: head of the family's profession, period (year) and type of settlement. For 2001-2016, modeling provided new different metrics through segmentation across the three levels: cities, towns and suburbs and rural areas.

The level of poor energy can now be assessed simultaneously in terms of value and quantity. Quantitative and qualitative modeling has been used separately, but in parallel. Metrics can be used to analyze the population's ability to withstand energy pressure in order to achieve macro-national targets for buildings. The poor energy level, in terms of value, is currently linked to the energy bill for heating-cooling buildings. Half of the total HH energy use in developed countries is for mobility (individual transport) and about $10 \%$ is for lighting and cooking. The rest of energy use is for the heating and cooling of residential buildings.

The further detailed modeling of maximum target energy use for buildings in a country can be differentiated according to every level of $\mathrm{C}, \mathrm{T} \& \mathrm{~S}$, and RA. This modeling is closely linked to macro targets at EU level. Next, the drastically reduced $\mathrm{CO} 2$ emissions levels for buildings (D31/EC/2010) can be determined differently per square meter of the building for the types of localities, with the modeling of each locality as a reference point. It is necessary that the established efficiency standards (limits) for the population's energy consumption and pollution are correlated with the necessary investments. These investments are added to 
the payment of the $\mathrm{CP} 04$ consumption cost bill. These new costs will be borne directly or through subsidies. In our research, energy assessment has two final goals: reducing fossil fuel consumption and simultaneously reducing pollution. Some cities have already set another target: neutral $\mathrm{CO} 2[8,12]$. Neutral $\mathrm{CO} 2$ Target is the result of community-level discussions [8], of expert reports about energy balance at city level [12] and of the final decision for energy and pollution balance [9].

The targets for the EU 20-20-20 strategy can be assessed for every settlement level in Romania for the 2005-2016 period. The spatial modeling of energy consumption for buildings in Romania, on the three types of human settlements, will ensure through quantitative and qualitative metrics the detailed substantiation of energy policies for buildings in Romania after 2020. The existence of different levels of energy use on the time's arrow will require the differentiated target levels of energy and related pollution for different large spatial communities. These targets will require differentiated measures for every type of settlement and household in the next three decades.

\section{Conclusions}

The modeling of energy was done for every combination of $\mathrm{HH}$, settlement, and for every year 20012016 for quantity and consumption expenditure on fuel for 192 cases. The IEA figures segmented for urban areas in Romania were modeled using quantities and monetary figures and can be compared with energy used for rural areas.

The biased decomposition of household energy use for cities and rural areas used for the Heating and Cooling Strategy (C\&HS) is solved. The new metrics for Romania have replaced the EU NUTS 3 classification as metropolitan, intermediary and rural regions with the proper classification of $\mathrm{C}, \mathrm{T} \& \mathrm{~S}$ and RA.

The trend of energy use in buildings differs by the type of settlement. It has annually grown by $2.35 \%$ for rural areas and by $0.24 \%$ for towns and suburbs. In urban areas (CT\&S), the high population density and energy consumption has already generated high spatial pollution.

The trend for energy per capita records increases in monetary terms by 8.84 times for RA, by 6.33 times for T\&S, by 5.81 times for cities and by 6.88 times per total. The trend of energy use for buildings in Romania between 2001-2016 is sharply increased for energy use in rural areas, only for pensioners and in monetary terms, by 9.21 times and 7.16 times per total CT\&SRA. In quantity terms for pensioners, it was by 1.51 times for RA and 1,17 times for total. The modeled metrics per capita for pensioners for energy use (quantity and income spent) for every type of settlement overcome the level of employees and average person (per total) starting with the 2014-2016 period. The high level for pensioners households shows us a lack of efficient devices and / or a use of low calorific fuel (and therefore more expensive in relativity). A $12-20 \%$ share of the energy bill only for buildings shows us the exceedance of the threshold. In Romania, the building energy use is $60-70 \%$ of the total energy use while in the developed countries it is $40-50 \%$.

The modeling of energy for buildings, using the quantities and consumption expenditure for Romanian cities, towns and suburbs and rural areas, offers a new differentiated landscape to policy decisions. The monetary efforts of the population for the new European Union efficiency targets can be assesed for Romania starting with the new metrics.

\section{Nomenclature}

\section{Acronyms}

CT\&SRA - Cities, Towns and Surburbs, Rural areas (together or separately);

$\mathrm{HH}$ - Households;

Mtoe - millions tonnes of oil equivalent;

koe - kilo of oil equivalent;

\section{Symbols}

$c$ - per capita;

$E, e-$ energy use, total, lei and koe;

$e$ - energy use, per capita, lei and koe ;

$f$ - fuel, by sixth types;

$i, j, k-\mathrm{HH}$, settlement or fuel type ;

$q$ - quantity, koe;

$v$ - monetary amount (value), lei;

$\mathrm{Nm}$ - number of month (12);

$\mathrm{NoHH}$ - number of household ;

$\mathrm{NoHHc}$ - number of HH per capita;

$p$ - unit price of fuel;

\section{References}

1. International Energy Agency (IEA), World energy outlook 2008, (IEA/OECD), Paris, France (2008)

2. N. Stern, Nature 530, 407-409, doi:10.1038/530407a

3. EUROSTAT, http://ec.europa.eu/eurostat, (2018)

4. K Amrane, pp 1003-1013, doi: 10.2790/14411, 1, (2013)

5. CofEC, http://eur-lex.europa.eu/legalcontent/EN/TXT/?uri=celex:52008DC0772.

6. EC, $\operatorname{COM}(2016) \quad 51$ final, https://ec.europa.eu/energy/sites/ener/files/docu ments/1_EN_ACT_part1_v14.pdf

7. EC, $\operatorname{COM}(2016) 51$ final $\}$, Brussels, SWD(2016) 24 final PART1/2, (2016)

8. N. Tillie et all, Journal of Green Building, Summer, Vol. 4, No. 3, pp. 103-112, https://doi.org/10.3992/jgb.4.3.103, (2009) 
9. Romanian National Agency for Environmental Protection, Local Environmental Permit no. 1/2017 for General Urban Plan of Timisoara, (2017)

10. N. Georgescu-Roegen, The Entropy Law and the Economic Process, Harvard University Press, Cambridge, Massachusetts, (1971)

11. National Institute of Statistics (NIS), http://www.insse.ro/cms/files/publicatii/CENG publicatie tabele.pdf (ro), 1, (2011)

12. Romanian National Agency for Environmental Protection, Report no. 2932 / 29.11.2016 (in Romanian/ro), (2016)

Annex

Table 1A Total energy use for residential buildings, Romania, 2001-2016, lei 2005

\begin{tabular}{|l|l|l|l|l|}
\hline Year & Total & $\mathbf{C}$ & $\mathbf{T} \& \mathbf{S}$ & $\mathbf{R A}$ \\
\hline 2001 & $3.6 \mathrm{E}+09$ & $1.5 \mathrm{E}+09$ & $9.6 \mathrm{E}+08$ & $1.2 \mathrm{E}+09$ \\
\hline 2002 & $5.1 \mathrm{E}+09$ & $2.1 \mathrm{E}+09$ & $1.4 \mathrm{E}+09$ & $1.5 \mathrm{E}+09$ \\
\hline 2003 & $6.3 \mathrm{E}+09$ & $2.6 \mathrm{E}+09$ & $1.7 \mathrm{E}+09$ & $2.0 \mathrm{E}+09$ \\
\hline 2004 & $7.8 \mathrm{E}+09$ & $3.0 \mathrm{E}+09$ & $2.0 \mathrm{E}+09$ & $2.7 \mathrm{E}+09$ \\
\hline 2005 & $9.6 \mathrm{E}+09$ & $3.9 \mathrm{E}+09$ & $2.5 \mathrm{E}+09$ & $3.2 \mathrm{E}+09$ \\
\hline 2006 & $1.1 \mathrm{E}+10$ & $4.6 \mathrm{E}+09$ & $2.9 \mathrm{E}+09$ & $3.7 \mathrm{E}+09$ \\
\hline 2007 & $1.2 \mathrm{E}+10$ & $4.7 \mathrm{E}+09$ & $3.0 \mathrm{E}+09$ & $3.9 \mathrm{E}+09$ \\
\hline 2008 & $1.5 \mathrm{E}+10$ & $5.5 \mathrm{E}+09$ & $3.7 \mathrm{E}+09$ & $5.3 \mathrm{E}+09$ \\
\hline 2009 & $1.6 \mathrm{E}+10$ & $5.8 \mathrm{E}+09$ & $3.9 \mathrm{E}+09$ & $5.9 \mathrm{E}+09$ \\
\hline 2010 & $1.7 \mathrm{E}+10$ & $6.1 \mathrm{E}+09$ & $4.2 \mathrm{E}+09$ & $6.3 \mathrm{E}+09$ \\
\hline 2011 & $1.7 \mathrm{E}+10$ & $6.3 \mathrm{E}+09$ & $4.3 \mathrm{E}+09$ & $6.4 \mathrm{E}+09$ \\
\hline 2012 & $1.8 \mathrm{E}+10$ & $6.7 \mathrm{E}+09$ & $4.6 \mathrm{E}+09$ & $6.7 \mathrm{E}+09$ \\
\hline 2013 & $1.9 \mathrm{E}+10$ & $7.0 \mathrm{E}+09$ & $4.9 \mathrm{E}+09$ & $7.0 \mathrm{E}+09$ \\
\hline 2014 & $2.0 \mathrm{E}+10$ & $7.3 \mathrm{E}+09$ & $5.2 \mathrm{E}+09$ & $7.6 \mathrm{E}+09$ \\
\hline 2015 & $2.2 \mathrm{E}+10$ & $7.7 \mathrm{E}+09$ & $5.6 \mathrm{E}+09$ & $8.3 \mathrm{E}+09$ \\
\hline 2016 & $2.2 \mathrm{E}+10$ & $7.8 \mathrm{E}+09$ & $5.9 \mathrm{E}+09$ & $8.7 \mathrm{E}+09$ \\
\hline
\end{tabular}

